\title{
Arguing to Solve Food Engineering Problems
}

\section{Prof. Tammara Ramírez Apud L., Universidad de las Americas Puebla}

I am a research professor imparting university level complex thinking. My speciality is the design of learning environments based on troubleshooting for critical thinking development.

\section{Dr. Judith Virginia Gutierrez Cuba}

$\mathrm{PhD}$. Science, Engineering and Technology Education. Postdoctoral Fellow at Universidad Nacional Autonoma de Mexico.

\section{Dr. Nelly Ramirez-Corona, Universidad de las Americas Puebla}

Nelly Ramírez-Corona is currently a Full Time Professor of Chemical Engineering at Chemical, Enviromental and Food Engineering Department, Universidad de las Americas, Puebla, México. Her teaching experience is in the area of Process Dynamics and Control, Kinetics, Catalysis and Reactor Design. She did her undergraduate studies in Chemical Engineering at the Universidad Autónoma de Tlaxcala, México, and his Master and Doctoral studies at the Instituto Tecnológico de Celaya, México. Her research interests are in the field of Process Systems Engineering, Bioprocess Modelling and Engineering Education. Her research labor has been reported on scientific international journals and presented in different national and international conferences.

\section{Prof. Aurelio Lopez-Malo, Universidad de las Americas Puebla}

Aurelio López-Malo is Professor and Past Chair, Department of Chemical, Food, and Environmental Engineering at Universidad de las Americas Puebla in Mexico. He teaches engineering and food science related courses. His research interests include emerging technologies for food processing, natural food antimicrobials, creating effective learning environments, and science, engineering and technology education for K-12.

\section{Dr. Enrique Palou, Universidad de las Americas Puebla}

Professor Palou is Director, Center for Science, Engineering, and Technology Education as well as Distinguished Professor and Past Chair, Department of Chemical, Food, and Environmental Engineering at Universidad de las Americas Puebla in Mexico. He teaches engineering, food science, and education related courses. His research interests include emerging technologies for food processing, creating effective learning environments, using tablet PCs and associated technologies to enhance the development of 21st century expertise in engineering students, and building rigorous research capacity in science, engineering and technology education. 


\title{
Arguing to Solve Food Engineering Problems
}

\begin{abstract}
Problem solving is an essential $21^{\text {st }}$ century skill, specifically the ability to solve different kinds of problems and to identify and ask significant questions ${ }^{1}$. The cognitive processes that enable learners to solve problems are the construction of problem schemas, analogical reasoning, causal reasoning, and argumentation ${ }^{2}$.
\end{abstract}

Argumentation is the means by which we rationally resolve questions, issues, and disputes and solve problems. An argument consists of a claim (solution) that is supported by principles (premises), evidence, and rebuttals against potential counterarguments. Fostering argumentation in problem-solving learning environments (PSLEs) promotes problem solving ${ }^{2,3}$. Therefore, we designed and implemented some PSLEs for several food engineering courses (from $1^{\text {st }}$ to $8^{\text {th }}$ semester) at Universidad de las Américas Puebla (UDLAP).

Problems vary in different ways, so different kinds of problems call on different conceptions and skills ${ }^{2-4}$. Based on those differences among problems, different kinds of food engineering problems were developed such as decision-making, troubleshooting/diagnosis, and design problems. For seven PSLEs' assignments an Argumentation Rubric (adapted from Jonassen ${ }^{2}$ ), was utilized to assess students' (n=81) argumentation skills, particularly adequacy of premises, credibility of premises, organization of arguments, quality of conclusions (claims), and writing (content/ideas). Four evaluators assessed student papers and videos. Furthermore, the most common method for assessing argumentation, protocol analysis of student essays or responses to questions, was performed by means of a qualitative data analysis software (Atlas.ti); identifying idea units within the essays or videos, and classifying those units with a coding scheme built from the Argumentation Rubric.

In average, students from the eighth (18.7) and ninth (18.1), semester had higher scores (from a total of 20 points) in the Argumentation Rubric than students from the first semester (14.1), since their credibility of premises, organization of arguments, and writing were adequate for first-year students but could be further improved as further detected by protocol analyses. Therefore in subsequent semesters, specific argumentation scaffolds during problem solving were implemented in order to further promote them and help students detect inconsistencies in their argumentations. Tested PSLEs favored the development of students' ability to argue throughout the curriculum. Very important differences (occurrence and quality) concerning argumentation among individual students from the same semester were detected by means of qualitative data analyses, mainly with regards to adequacy of premises, organization of arguments, and quality of claims. Our results validate that argumentation is an essential skill in learning to solve studied food engineering problems as well as a powerful method for assessing problem-solving ability for both ill-structured and well-structured problems alike as previously reported ${ }^{3}$ for other disciplines. 


\section{Introduction}

The main task of a food engineer (FE) is to design and operate processes to transform raw materials into final products, particularly with the aim to control, prevent, or delay spoilage caused by chemical reactions, physical effects, and/or biological activity. At Universidad de las Américas Puebla (UDLAP), food engineering students develop the knowledge and skills required to function in the different fields of FE. The Food Engineering program from UDLAP is approved by the Institute of Food Technologists (IFT) and accredited by the Consejo de Acreditación de la Enseñanza de la Ingeniería (CACEI), which is the Mexican peer-accrediting agency of the US ABET. Graduates of UDLAP's Food Engineering program (FE) shall attain thirteen outcomes; eleven of them are similar to ABET Criterion 3 (a-k) program outcomes ${ }^{6}$ and the other two are as follows: "an ability to communicate effectively in English in written form" and "an ability to rationally use information and communication technologies as learning tools, and to find and manage important information"; as well as specific IFT core competencies ${ }^{7}$ regarding five major areas: food chemistry and analysis; food safety and microbiology; food processing and engineering; applied food science; and success skills.

Problem solving is one of the features that distinguish engineers, which often are hired, rewarded and promoted in their jobs by their skills to solve problems ${ }^{4,5}$. However, real engineering problems are often different, in many aspects, from problems that engineering students frequently solve in their classroom ${ }^{2,4,5}$. Therefore, the primary purpose of engineering education should be to engage and support learning to solve problems ${ }^{2,4}$. Hence, we designed and implemented several problem-solving learning environments (PSLEs), a term that represents problem-solving instruction in a more open-ended way than problem-based learning ${ }^{2}$. Through PSLEs, students find relationship between knowledge and the needs of their professional environment. In this way, learning becomes meaningful and is not seen as accumulation of information. In addition, other skills can be developed such as teamwork, and allows the appropriation of a mental process to address problems of their profession. Problem solving is a schema-based activity ${ }^{2-4}$; that is, in order to solve problems, learners must construct schemas for different kind of problems. Constructing models for problem solving greatly facilitates schema development. Having constructed a robust schema for different kinds of problems, learners are better able to transfer their problem-solving skills. Learning to solve problems requires practice in solving problems, not learning about problem solving ${ }^{2}$. PSLEs assume that learners must engage with problems and attempt to construct schemas of problems, learn about their complexity, and mentally wrestle with alternative solutions ${ }^{2,3}$.

According to Jonassen ${ }^{2-4}$, problem solving solutions should not be more important than understanding the process utilized to solve the problem. PSLEs must focus on student experience in developing a process to achieve a solution ${ }^{8}$. Troubleshooting problems allow students to act as professionals, solving real situations they could encounter and not just being accumulators of knowledge. Several educators consider that including troubleshooting in a course helps students to learn the "know-how", not only know how to apply academic knowledge, 10. 
Argumentation is one of the most important cognitive processes engaged in solving most kinds of problems ${ }^{3}$. In most PSLEs, problem solving may be engaged by including some form of argumentation in the environment ${ }^{2}$. Purposes of those argumentation activities are to support better problem solving or to assess students' understanding of both, domain content and problem-solving skills. Argumentation may be used to justify problem interpretations ${ }^{2}$. During the studied courses, following the presentation of a case as problem to solve by the teacher, students utilized cases as analogues, cases as prior experiences, or cases as alternative perspectives $^{2-4}$ to characterize what kind of problem was being solved and what important questions or issues need to be addressed. All of these are open to interpretation and therefore subject to argumentation. So, students were required to construct arguments in support of their problem interpretations. Arguments should also be used to help students to justify alternative solutions to the problem ${ }^{2}$. Clearly, dialectic forms of argumentation are appropriate. During the studied courses, individual students or groups of students had to make claims about the "best" solution and justify it in terms of warrants or case evidence which they garnered from the case as presented by the instructor or from their research outside classroom. The instructor provided several prompts as argument scaffolds, helping students to construct a coherent argument. Some prompts and directions were specific to the problem case they were discussing.

Argumentation is the means by which we rationally resolve questions, issues, and disputes and solve problems ${ }^{2,11-14}$. An argument consists of a claim (solution or conclusion) that is supported by principles (warrants), evidence (premises), and rebuttals against potential counterarguments. Fostering argumentation in PSLEs promotes problem solving. Arguing for alternative interpretations or solutions to problems is especially important when addressing ill-structured problems ${ }^{2-4,12,13}$.

One of the most comprehensive conceptions of the skills of argument is provided by Kuhn ${ }^{12-14}$, who proposed thinking as a form of formulating and weighting the arguments for and against a course of action, a point of view, or a solution to a problem ${ }^{12}$. She identified five essential skills of argumentation:

- Generate causal theories to support claims (supportive theory)

- Offer evidence to support theories (evidence)

- Generate alternative theories (alternative theory)

- Envision conditions that would undermine the theories they hold (counterarguments)

- Rebut alternative theories (rebuttal)

According to Kuhn ${ }^{12}$, an argument can be considered strong if it contains these components; while for Blair and Johnson ${ }^{11}$, a good argument must meet the following three criteria:

- Adequate relationship between the contents of the premises and the conclusion

- Premises provide enough evidence for the conclusion

- Premises are true, probable, or reliable 
These criteria are sufficient for judging the effectiveness of most arguments and useful to know how students developed their ability to argue throughout PSLEs ${ }^{15}$. In a previous work ${ }^{16}$, initial implementation of three PSLEs was exploratory and intended to provide formative evaluation. PSLEs applied in that first implementation, favored the development of first-semester food engineering students' ability to argue. In general, their quality of conclusions (claims) were good, while their credibility of premises, organization of arguments, and writing (content/ideas) were adequate for first-semester students but it was established that we could further improve their performance. It was suggested ${ }^{16}$ that in subsequent semesters more instructor support was needed regarding adequacy of premises in order to further promote them and help students detect, by means of specific argumentation scaffolds during problem solving ${ }^{17}$, inconsistencies in their argumentations due to inadequate premises. Hence, in this work we built several PSLEs for subsequent semesters to further engage and support students in learning how to solve problems by practicing solving problems ${ }^{5}$.

\section{Methodology}

PSLEs were developed by following the design activities proposed by Jonassen ${ }^{2}:$ 1) first we interacted with the instructors of the studied courses to identify and articulate problems relevant to the discipline; 2) working with corresponding instructor, we analyzed problems, first by creating a causal model of the problem space; then we conducted an activity theory analysis to identify the historical, cultural, experiential factors that affect problem solving on the chosen course $^{10} ; 3$ ) after selecting adequate problems, we determined what kind of problems were each one of them; 4) then constructed case supports and cognitive scaffolds for each selected problem; 5 ) to then construct each PSLE that included some combination of case components and cognitive strategies; 6) finally developed PSLEs were implemented and assessed.

Problems vary in different ways, so different kinds of problems call on different conceptions and skills; consequently learning methods should also vary ${ }^{2-4}$. Based on those differences among problems, different kinds of food engineering problems were developed, including story problems (utilized as worked examples by the teacher), decision-making problems, troubleshooting/diagnosis problems, and design problems. Through the incorporation of PSLEs the studied courses pretend to recognize the importance of problem solving and evaluate studied courses' learning outcomes through the progress of solutions (and corresponding argumentations) posed by the students.

Several PSLEs were implemented and seven of them were assessed, work products from a total of 81 undergraduate students were analyzed, 24 students from first semester (Falls 2011, 2012, and 2013), 18 students from fourth semester (Spring 2013), 23 students from the seventh semester (spring 2013), and 16 students from the eighth semester (spring 2013). The courses where PSLEs were applied are:

- $\quad$ LIA1011, Introduction to Food Engineering, $1^{\text {st }}$ semester

- IQ250, Modeling and Simulation in Chemical Processing Engineering, $4^{\text {th }}$ semester 
- IA442, Food Processing II, $7^{\text {th }}$ semester

- $\quad$ IA444, Design and Development of Food Products and Processes, $8^{\text {th }}$ semester

For the seven PSLE assignments an Argumentation Rubric (Table 1, adapted from Jonassen²), was utilized to assess students' argumentation skills, particularly adequacy of premises, credibility of premises, organization of arguments, quality of conclusions (claims), and writing (content/ideas).

Table 1. Argumentation Rubric (adapted from Jonassen²)

\begin{tabular}{|c|c|c|c|c|}
\hline & $\begin{array}{c}\text { Needs improvement } \\
1\end{array}$ & $\begin{array}{c}\text { Fair } \\
2\end{array}$ & $\begin{array}{c}\text { Good } \\
3\end{array}$ & $\begin{array}{c}\text { Excellent } \\
4\end{array}$ \\
\hline Adequacy of Premises & $\begin{array}{l}\text { No premises stated; only } \\
\text { unsupported conclusions. }\end{array}$ & $\begin{array}{l}\text { Few premises stated; } \\
\text { most unclear. }\end{array}$ & $\begin{array}{l}\text { Most premises stated } \\
\text { explicitly; most clear. }\end{array}$ & $\begin{array}{l}\text { All premises stated } \\
\text { explicitly. }\end{array}$ \\
\hline Credibility of Premises & $\begin{array}{l}\text { Sources of evidence are } \\
\text { weak, filled with } \\
\text { unsupportable evidence } \\
\text { and propaganda. }\end{array}$ & $\begin{array}{l}\text { Sources of evidence } \\
\text { are questionable or } \\
\text { origin is unknown. }\end{array}$ & $\begin{array}{l}\text { Sources of evidence } \\
\text { mostly valid with } \\
\text { limited amounts of } \\
\text { unknown data. }\end{array}$ & $\begin{array}{l}\text { Sources of evidence } \\
\text { (personal, written, etc.) } \\
\text { are unimpeachable; } \\
\text { accepted as fact. }\end{array}$ \\
\hline $\begin{array}{l}\text { Organization of } \\
\text { Arguments }\end{array}$ & $\begin{array}{l}\text { Arguments are } \\
\text { indistinguishable; } \\
\text { unorganized; do not } \\
\text { support each other. }\end{array}$ & $\begin{array}{l}\text { Arguments identified; } \\
\text { relationships to each } \\
\text { other not obvious. }\end{array}$ & $\begin{array}{l}\text { Arguments articulated } \\
\text { but partially } \\
\text { integrated; } \\
\text { relationships to each } \\
\text { other usually positive. }\end{array}$ & $\begin{array}{l}\text { Each argument } \\
\text { separated; sequenced } \\
\text { logically to support } \\
\text { solution to problem. }\end{array}$ \\
\hline $\begin{array}{l}\text { Quality of Conclusions } \\
\text { (claims) }\end{array}$ & $\begin{array}{l}\text { Conclusions unrelated to } \\
\text { problem needs or } \\
\text { solution. }\end{array}$ & $\begin{array}{l}\text { Few conclusions relate } \\
\text { to problem needs or } \\
\text { solutions; inconsistent } \\
\text { relationships. }\end{array}$ & $\begin{array}{l}\text { Conclusions relate to } \\
\text { problem generally, } \\
\text { but some unclear; } \\
\text { usually support stated } \\
\text { solution. }\end{array}$ & $\begin{array}{l}\text { All conclusions } \\
\text { relevant to problem; } \\
\text { support solutions; } \\
\text { related to needs. }\end{array}$ \\
\hline Writing (content/ideas) & $\begin{array}{l}\text { Writing is extremely } \\
\text { limited in } \\
\text { communicating } \\
\text { knowledge, with no } \\
\text { central theme. }\end{array}$ & $\begin{array}{l}\text { Writing does not } \\
\text { clearly communicate } \\
\text { knowledge. The } \\
\text { reader is left with } \\
\text { questions. }\end{array}$ & $\begin{array}{l}\text { Writing is purposeful } \\
\text { and focused. Piece } \\
\text { contains some details. }\end{array}$ & $\begin{array}{l}\text { Writing is confident } \\
\text { and clearly focused. It } \\
\text { holds the reader's } \\
\text { attention. Relevant } \\
\text { details enrich writing. }\end{array}$ \\
\hline
\end{tabular}

The following paragraphs describe each of the assessed PSLEs:

Problem 1. Troubleshooting/Diagnosis Problem ${ }^{16}$ for the first semester course You attended a big party where they served a wide variety of dishes (appetizers, entrees, salads, soups, main courses (made from meat, fish, seafood, and chicken), desserts, and pastries. During 
the days after the party, your friends heard that several of the guests became ill. Some of them mentioned that the disease was related to food consumption and in particular with the organism mentioned below (a different microorganism was assigned to each student, microorganisms include: Staphylococcus aureus, Listeria monocytogenes, Salmonella, Clostridium perfringens, Escherichia coli O157:H7, among others).

As a specialist in Food Engineering, you need to prepare a document (3 pages maximum) explaining what could have happened? Must contain some details (see below) to help your friends understand what happened:

- How common is this disease?

- Name at least two ideas (premises) about what do you think happened in order for the guests to get sick

- Characteristics of the organism

- What are the characteristics of the disease, what are the symptoms?

- Related foods and conditions that promote the presence of the organism, as well as conditions under which the food was contaminated

- Groups of people who are most affected

- Infectious dose to cause disease

- State your conclusion about what happened to the food served that day

- What is your recommendation to avoid this problem?

You can consult as a starting point the information contained in the class website. However, your final document should include additional references.

Problem 2. Design Problem/Video ${ }^{16}$ for the first semester course

You are requested to make a video explaining a process of food preservation (food processing). Some of your friends/colleagues did not know the important steps to transform and preserve food using this technology (a different technology was assigned to each student, including: freezedrying, drying, cheese-making, canning, gum technology, among others).

As a specialist in Food Engineering you need to prepare a document (3 pages maximum) and a video (3-5 $\mathrm{min}$ ) that explain and help your friends/colleagues to understand the process.

- In which food process is based this technology?

- What equipment can be used?

- Description of equipment

- How does it work this technology?

- Which foods can be processed / transformed with this technology? Include as many examples as you can

You can consult as a starting point the information contained in the class website. However, your final document should include additional references. 
Problem 3. Decision-Making/Strategic Performance Problem ${ }^{16}$ for the first semester course For this assignment you are required to prepare a written report (3 pages) and a 5-7 minute presentation about nutrition requirements and diet among your friends/colleagues:

- Apply the questionnaire (gender, height, weight, daily physical activity, foods consumed in one day) to at least 10 people

- Analyze the results obtained regarding caloric needs

- Analyze information about the diet of your friends/colleagues

- Analyze and discuss the data obtained

o Identify deficiencies and/or abuses in at least three nutrients and propose solutions (food to eat or reducing their consumption) according to your findings

You can consult as a starting point the information contained in the class website. However, your final document should include additional references.

Problem 4: Decision-Making/Strategic Performance Problem for the fourth semester course Develop an application in Excel ${ }^{\mathrm{TM}}$ to display an interactive environment easy to use where we can observe a phase diagram of a compound of choice from a defined list: Pressure vs. Temperature from the triple point to the critical point and Pressure vs. Volume for the gas phase at a given temperature, which must be greater than the saturation. Raise two thermodynamic assumptions (assessment of the state of the compound) that must be considered to build phase diagrams and determine the gas phase volume. Explain the characteristics of your application based on the literature (include list of references). Develop two proposals, organizing information in the form of an algorithm to develop the application, and analyze your two proposals evaluating the initial premises and conclude which is the best for developing the required application.

Problem 5: Decision-Making/Strategic Performance Problem for the seventh semester course The problem asks students first to review the Official Mexican Standard (NOM) entitled NOM043-SSA2-2005: Basic Health Services. Promotion and Health Education in Food Matters. Criteria to Provide Guidance. Then, after in-class discussion, students realize that they can participate and join efforts to provide guidance, establish criteria, and report on these issues. Therefore students were asked the following:

Choose from the general or specific provisions, which are raised by the standard and from your perspective propose two options to support implementation of the NOM. In a document of two pages maximum: clearly present what do you propose and why you consider them good solutions, make a brief justification for your assumptions grounded in research papers, answering at least the following question: which are the criteria that they must comply or meet to reach a solution to the problem? (Quoted and referenced appropriately); Present the pros and cons of each of your proposed solutions; taking into account the criteria that must be met. Clearly identify the hazards involved in each of the two solutions, and write your conclusions, choosing the solution that you consider the best option to solve the problem that you analyzed. 
Problem 6: Troubleshooting/Diagnosis Problem for the eight semester course

After watching the documentary Food Inc., write a report that includes at least the following: What caught your attention when viewing the documentary? Why? From your point of view as a Food Engineer, what important points need to be further developed or need to present more information to better inform the public? From your perspective, which documentary segments are similar to what happens in Mexico? Propose a solution, plausible in Mexico, for these segments.

Problem 7: Troubleshooting/Diagnosis Problem for the eight semester course

You need to choose an issue on a food related system or product that needed to be researched and then propose an experimental design at two levels where the effect of at least three factors on one or more responses that are of interest will be investigated. In your report you need to respond to the following: The purpose of the experimental design - what problem (system/product) will be investigated and why? Raise at least two premises or assumptions on which you expose what do you think is the problem and what is causing it. Explain the characteristics of the system/product and how should be its desirable properties/attributes. What would your proposal investigate with regards to the system/product? Provide justification for the selection of factors/levels. Explain what you will need to be able to carry out your proposal. Conclusions need to be included.

Students' papers and videos were assessed by four evaluators (corresponding course instructor, a professor from UDLAP's Food Engineering faculty, and two students from UDLAP's PhD program in Science, Engineering, and Technology Education). Furthermore, the most common method for assessing argumentation, protocol analysis of student essays or responses to questions, was performed by means of a qualitative data analysis software; identifying idea units within the essays or videos, and classifying those units with a coding scheme built from the Argumentation Rubric (Table 1).

For qualitative analysis, Atlas.ti software was utilized to sort and categorize the information obtained. This software allowed to organize every student assignment and facilitated the selection of units of meaning and to order these into categories. Each assignment was converted to a PDF file, because the software allows analyzing data from a PDF or Word ${ }^{\mathrm{TM}}$ file. Once PDF files were obtained, a Hermeneutic Unit was created, which is a folder situated in the hard drive of the computer and is composed of primary documents, in this case, the PDF files. The analysis was started codifying the primary documents, selecting text fragments and identifying units of meaning, assigning a specific code and dividing them in the categories previously selected from the Argumentation Rubric (Table 1). The software allowed a qualitative analysis and graphical representation of the results in Excel ${ }^{\mathrm{TM}}$, once every primary document was coded.

\section{Results and discussion}

In average (Figure 1), students from the eighth (18.7) and seventh (18.1), semester had significantly $(\mathrm{p}<0.05)$ higher scores (from a total of 20 points) in the Argumentation Rubric 
(Table 1) than students from the first semester. For first-semester students, their credibility of premises, organization of arguments, and writing were adequate but could be further improved as further detected by protocol analyses. Therefore in subsequent semesters, specific argumentation scaffolds during problem solving were implemented in order to further promote them and help students detect inconsistencies in their argumentations. Tested PSLEs favored development of students' ability to argue through the curriculum (Figure 1).

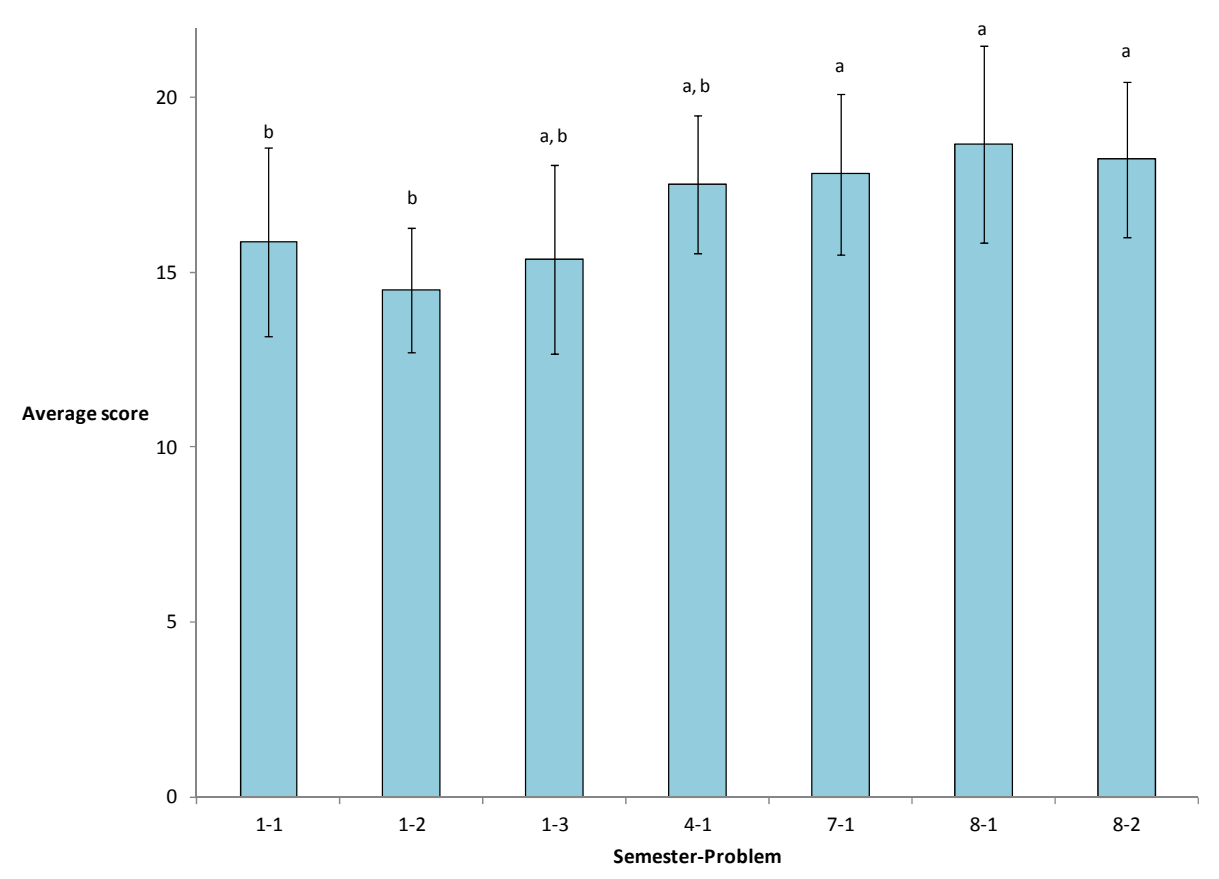

Figure 1. Mean argumentation (Table 1) scores (and standard deviations) obtained by students for each tested problem (1-1: troubleshooting/diagnosis, 1-2: design, 1-3: decision-making/strategic performance) in the $1^{\text {st }}$ semester studied course, (4-1: decision-making/strategic performance) in the $4^{\text {th }}$ semester studied course, (7-1: decision-making/strategic performance) in the $7^{\text {th }}$ semester studied course, (8-1: troubleshooting/diagnosis and 8-2: troubleshooting/diagnosis) in the $8^{\text {th }}$ semester studied course. Bars with the same letter on the top are not significantly different $(\mathrm{p} \geq 0.05)$.

As shown in Figure 1, in every studied semester the level of argumentation of students was high (in most cases above 15 points out of 20), but an increased level was also noticed as students progressed in their studies, which means that students further developed their argumentation skills through solving food engineering problems. This is also evident (Figure 1) for the different types of tested problems; for example, between $1^{\text {st }}$ and $8^{\text {th }}$ semester troubleshooting/diagnosis problems $1-1$ and $8-1 / 8-2$ or among decision-making/strategic performance problems $1-3\left(1^{\text {st }}\right.$ semester $)$, 4-1 ( $4^{\text {th }}$ semester $)$, and 7-1 ( $7^{\text {th }}$ semester $)$.

Tested kinds of problems call on different conceptions and skills ${ }^{2-4}$. Troubleshooting is one of the most common forms of everyday problem solving ${ }^{2}$. Although troubleshooting is most commonly taught as a procedure, it requires a combination of domain and system knowledge 
(conceptual models of the system including system components and interactions), flow control, fault states (fault characteristics, symptoms, contextual information, and probabilities of occurrence); troubleshooting strategies such as search and replace, serial elimination, and space splitting; and fault testing procedures ${ }^{2,3,5,16}$.

The first part of diagnosis-solution problems, diagnosis, is quite similar to troubleshooting ${ }^{2}$. Most diagnosis-solution problems require identifying a fault state, just like troubleshooting. However, in troubleshooting, the goal is to repair the fault and to get the system back online as soon as possible, so the solution strategies are more restrictive. Diagnosis-solution problems usually begin with a fault state similar to troubleshooting. In a spiral of data collection, hypothesis generation and testing, the problem-solver focuses in a differential diagnosis to suggest a solution. Frequently, there are multiple solutions and solution options that are imposed by the problem. It is this ambiguity in solution options that distinguishes diagnosis-solution problems from troubleshooting. Note that as problem-solvers gain experience, the diagnostic process becomes more of a process of pattern recognition ${ }^{2,3,16}$.

Some of the most important characteristics of troubleshooting/diagnosis problems that were used for design tested PSLEs are ${ }^{2-5,16}$ :

- Appear ill-defined because the troubleshooter must determine what information is needed for problem diagnosis

- Require deep-level understanding of the system being troubleshot

- Usually possess a single fault state, although multiple faults may occur simultaneously

- Rely most efficiently on experience-based rules for diagnosing most of the cases, making it more difficult for novices to learn

- Require learners to make judgments about the nature of the problem

- Vary significantly in terms of system complexity

In a study on the development of argumentation through troubleshooting, Jonassen ${ }^{9}$ proposed that argumentation is essential to identify the real specific problem and to decide on the most appropriate solution when working in teams. The ability to effectively argue from different positions is needed to diagnose the environment and propose the best solution ${ }^{17}$.

Decision-making problems usually require that problem solvers select a solution from a set of alternative solutions ${ }^{2}$. Traditional conceptions of decision making posit a set of alternative criteria that decision makers work through in order to identify the optimal solution. Those criteria may be provided to the problem solver(s), or the solver(s) may have to identify the most relevant criteria. Everyday life is replete with decision-making problems. Businesses also daily solve many decision-making problems. Though these problems typically require selecting one solution, the number of decision factors to be considered in deciding among those solutions as well as the weights assigned to them can be very complex ${ }^{2-5,16}$. 
According to Yates and Tschirhart ${ }^{18}$, there are many different kinds of decisions, including:

- Choices: where you select a subset from a larger set of alternatives

- Acceptances/rejections: a binary choice in which only one specific option is acknowledged and must be accepted or not

- Evaluations: statements of worth that are backed up with commitments to act

- Constructions: attempts to create ideal solutions given available resources

Decisions, regardless of kind, include the following features ${ }^{18}$ :

- Action: Action is taken by the decision maker, typically involving a selection

- Commitment: Decisions are made as soon as there is a commitment to act

- Intention: Decisions are driven by a purpose or intention (usually thought to be optimization of value, benefit, or utility)

- Satisfying results: Decisions that provide the greatest utility are the most satisfying

- Specified individuals: Decisions are made for someone by someone

Strategic performance entails real-time, complex activity structures where the performers apply a number of tactical activities to meet a more complex and ill-structured strategy, usually under significant time pressure ${ }^{2}$. In order to achieve the strategic objective, the performer applies a set of complex tactical activities designed to meet strategic objectives. Typically there are a finite number of tactical activities that have been designed to accomplish the strategy; however, the mark of an expert tactical performer is his or her ability to improvise or construct new tactics on the spot to meet the strategy. Strategic performances can be quite complex yet performed in real time. The options can be quite numerous and their implementation quite complex ${ }^{2,3,16}$.

Perhaps the most ill-structured kind of problem is design ${ }^{2,9}$. Design problems require applying a great deal of domain knowledge with a lot of strategic knowledge. They possess multiple solutions, with multiple solution paths. Perhaps the most vexing part of design problems is that they possess multiple criteria for evaluating solutions, and these criteria are often unknown. Ultimately, the designer must please the client; however, the criteria for an acceptable design are usually unstated. Design problems often require the designer to make judgments about the problem and to defend them or to express personal opinions or beliefs about the problem; so illstructured problems are uniquely human interpersonal activities ${ }^{2,9,16}$.

Very important differences (occurrence and quality) concerning argumentation among individual students from the same semester were detected by means of qualitative data analyses, mainly with regards to adequacy of premises, organization of arguments, and quality of claims as can be clearly seen in Figure $2\left(1^{\text {st }}\right.$ semester students A, B, C, and D as well as $8^{\text {th }}$ semester students E, F, G, and H). 


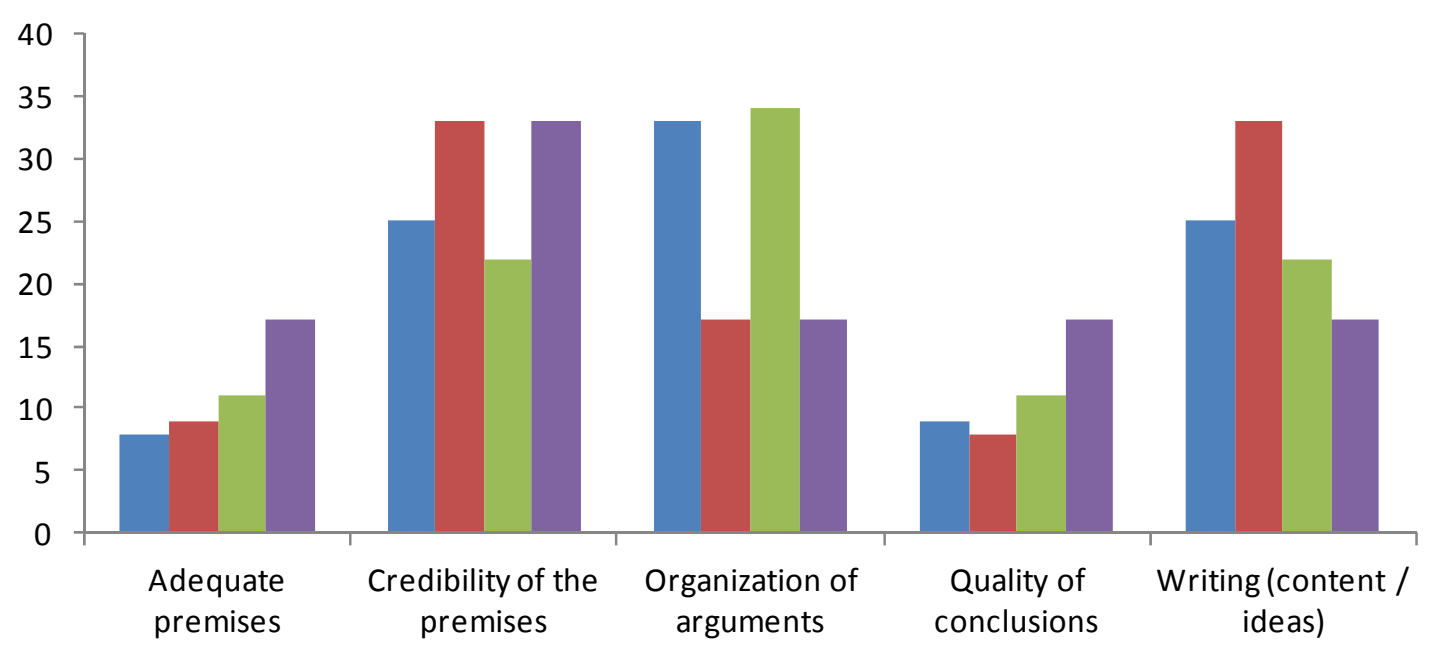

Student-E $\quad$ Student-F $\quad$ Student-G $\quad$ Student-H

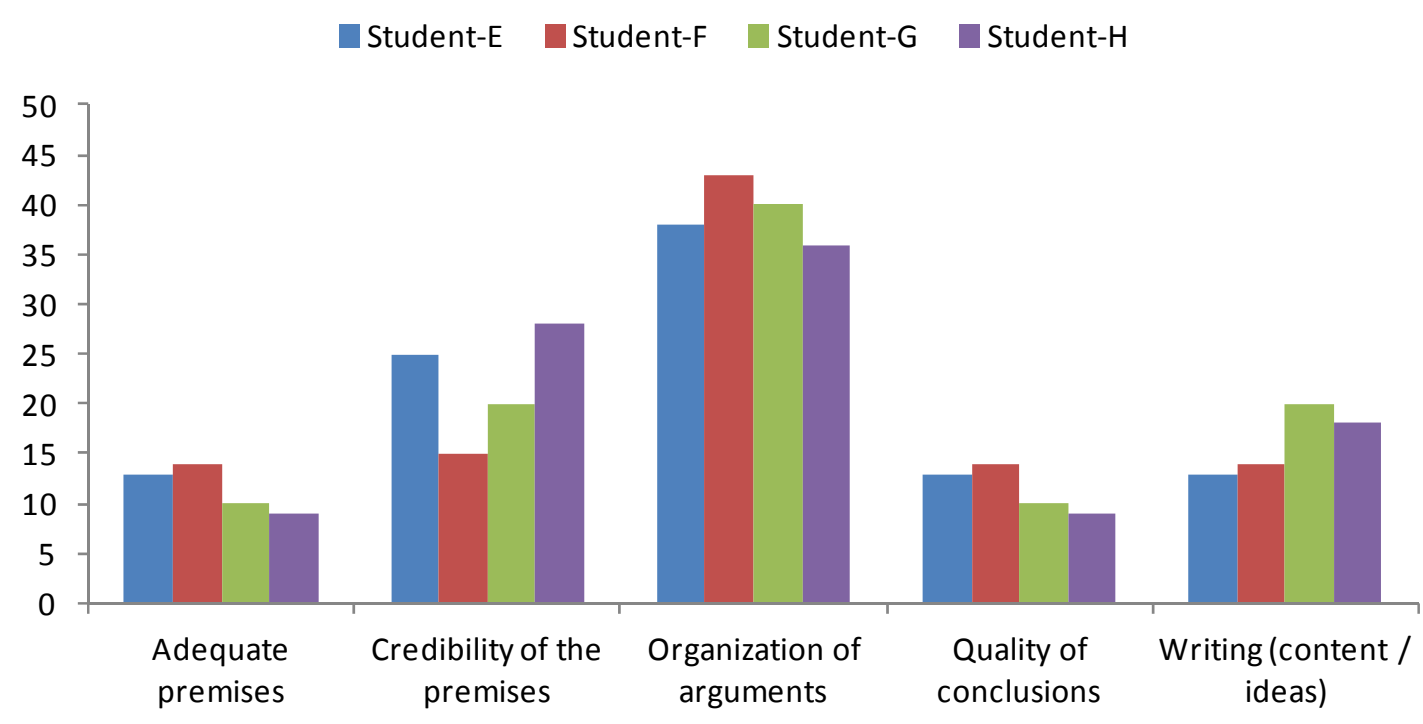

Figure 2. Percentage of argumentation criteria (Table 1) attainment by selected $1^{\text {st }}$ semester students (a) while solving problem number 1 (Troubleshooting/Diagnosis) as well as by selected $8^{\text {th }}$ semester students (b) while solving problem number 6 (Troubleshooting/Diagnosis).

Figures 3-5 present mean values for selected problems and courses. As can be observed in Figure 3 , adequate premises (in general, $11 \%$ of the document was allocated to this part) were raised specifically. The credibility of the premises (in general, $29 \%$ of the document was allocated to this part) that are the theoretical arguments supporting the argumentation was adequate. Organization of the arguments (in general, $26 \%$ of the document was allocated to this part) was divided into several sections to present information logically. The quality of the conclusions (in general, $11 \%$ of the document was allocated to this part) indicated that students were able to issue a concrete conclusion. Writing (in general, $23 \%$ of the document was allocated to this part) has a high percentage and includes contributions that enrich the document, expressed by student ideas in relation to the problem being analyzed (several of the party guests became ill). 
- Adequate premises

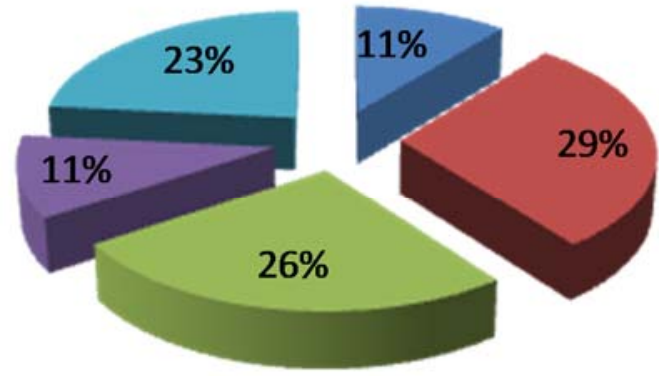

\author{
Credibility of the \\ premises \\ Organization of \\ arguments \\ - Quality of \\ conclusions \\ Writing (content / \\ ideas)
}

Figure 3. Percentage of argumentation criteria (Table 1) attainment by $1^{\text {st }}$ semester students while solving problem number 1 (Troubleshooting/Diagnosis).

Adequate premises

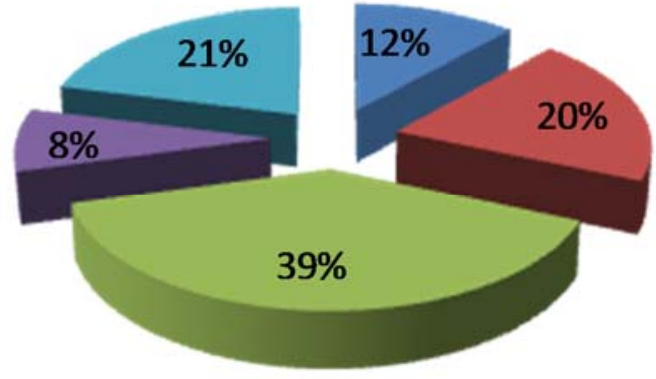
Credibility of the premises
Organization of arguments
- Quality of conclusions
Writing (content / ideas)

Figure 4. Percentage of argumentation criteria (Table 1) attainment by $7^{\text {th }}$ semester students while solving problem number 4 (Decision-Making/Strategic Performance).

Figure 4 presents the distribution percentage of Argumentation Rubric (Table 1) criteria attained by $7^{\text {st }}$ semester FE students solving problem 4. In regards to the criterion "adequate premises", students proposed two specific solutions to address the stated problem. With regards to "credibility of the premises" since the problem involved an analysis of a Mexican Official Standard, students only investigated on this subject. Students were able to organize the information according to their interpretation of the NOM, generating an extensive analysis of how they interpret to provide guidance, criteria, and report on these issues. Students adequately included their own ideas on the subject ("writing"). 
In the documents submitted by students it was observed an information organization that enabled them to propose their best solution. Each paper shows a theoretical framework that sustains their two proposals, as well as analysis and organization to logically present their findings. Using this PSLE, students were able to incorporate new knowledge and apply it to generate proposals for solving the stated problem. Perrenet et al. ${ }^{19}$ suggested that students, through problem solving, self-addressed their learning and take responsibility for generating a process of thinking and learning different subjects, through self-assessment and monitoring their understanding to improve their learning strategies. Through this particular PSLE, students guided their own learning and demonstrated its application.

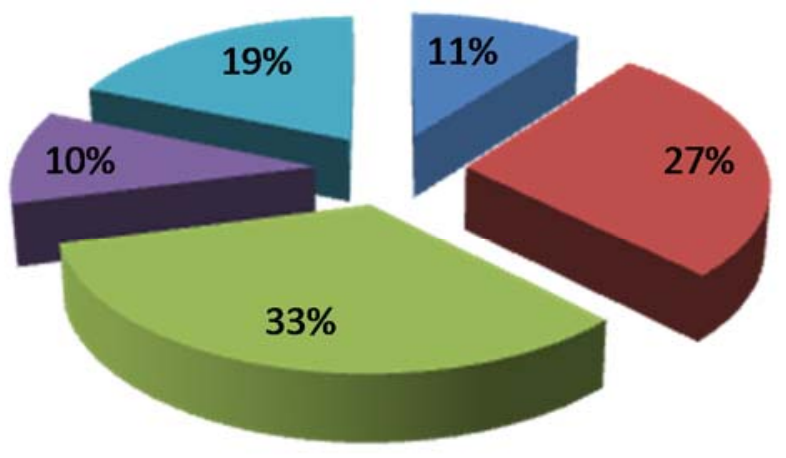

\title{
Adequate premises
}

\author{
Credibility of the \\ premises \\ Organization of \\ arguments \\ Quality of conclusions
}

Writing (content / ideas)

\begin{abstract}
Figure 5. Percentage of argumentation criteria (Table 1) attainment by $8^{\text {th }}$ semester students while solving problem number 6 (Troubleshooting/Diagnosis).
\end{abstract}

Figure 5 presents the distribution percentage of Argumentation Rubric (Table 1) criteria attained by $7^{\text {st }}$ semester FE students solving problem 6 (reflect on the Food Inc. documentary). Most of students were at least on level 3 of the rubric but several of them were assessed with level 4 in many of the criteria. That means most of the 8th semester students were able to state explicitly their premises, for which sources of evidence (personal, written, etc.) were unimpeachable and accepted as fact. Their arguments were separated; sequenced logically to support solution to the stated problem. Most of their conclusions were relevant to problem, support their solutions, and are related to problem needs. Finally, most of their writing was confident and clearly focused. It held the reader's (evaluators) attention. Relevant details were present that enriched their writing.

\section{Final remarks}

Our results validate that argumentation is an essential skill in learning to solve studied food engineering problems as well as a powerful method for assessing problem-solving ability for both ill-structured and well-structured problems alike as previously reported ${ }^{2-5}$ for other 
disciplines. Embedding argumentation in science (engineering) learning environments enhances conceptual and epistemic understanding and helps to make scientific (engineering) reasoning visible $^{20}$. According to Nussbaum and Sinatra ${ }^{21}$, constructing arguments promotes conceptual change because of the high conceptual engagement in students.

Future empirical research should explore whether the results concerning argumentation while solving problems found in this study generalize to other kinds of engineering domains as well as different populations. Given the exploratory nature of this study, we recognize the limitations of generalizability of this study. However, to the degree that engineering education embraces the teaching of arguing to solve problems to better prepare students for functioning in everyday and professional contexts, a better understanding of studied processes is required. Much more engineering education research on argumentation while solving different kinds of problems is needed.

\section{Acknowledgments}

Author Ramírez Apud acknowledges financial support for her PhD studies from the National Council for Science and Technology of Mexico (CONACyT) and Universidad de las Américas Puebla. Author Gutiérrez Cuba gratefully acknowledges a postdoctoral fellowship from CONACyT.

\section{References}

[1] The Partnership for 21st Century Skills. 2012. 21st Century Skills Framework. Available (April 5, 2015) at http://www.p21.org/about-us/p21-framework

[2] Jonassen, D. H. 2011. Learning to Solve Problems: A Handbook for Designing Problem-Solving Learning Environments. Routledge: New York.

[3] Jonassen, D. H. 2010. Assembling and Analyzing the Building Blocks of Problem-Based Learning Environments, in Handbook of Improving Performance in the Workplace, Volume One: Instructional Design and Training Delivery (K. H. Silber and W. R. Foshay, eds.), John Wiley \& Sons: Hoboken, NJ.

[4] Jonassen, D. H., Strobel, J., and Lee, C. B. 2006. Everyday problem solving in engineering: Lessons for engineering educators. Journal of Engineering Education, 95(2): 1-14.

[5] Ramirez Apud, Z., Ramirez-Corona, N., López-Malo, A., and Palou, E. 2012. Implementing Problem-solving Learning Environments in a Kinetics and Homogeneous Reactor Design Course. Proceedings of the 2012 ASEE Annual Conference and Exposition, San Antonio, TX, June 10 - 13.

[6] ABET. 2015. Criteria for Accrediting Engineering Programs Effective for Reviews During the 2015-2016 Accreditation Cycle. Engineering Accreditation Commission. ABET. Available (April 5, 2015) at: http://www.abet.org/uploadedFiles/Accreditation/Accreditation_Step_by_Step/Accreditation_Documents/Curr ent/2015-2016/E001\%2015-16\%20EAC\%20Criteria\%2011-7-14.pdf

[7] IFT. 2012. Resource Guide for Approval and Re-Approval of Undergraduate Food Science Programs. Institute of Food Technologists. Available (April 5, 2015) at:

http://www.ift.org/ /media/Knowledge $\% 20$ Center/Learn $\% 20$ Food $\% 20$ Science/Become $\% 20 \mathrm{a} \% 20 \mathrm{Food} \% 20 \mathrm{Sci}$ entist/Resources/Guide_Approval_UndergradFoodSci.pdf

[8] Jonassen, D. H., Schmidt, M. A., Miller, W., and Neumeyer, G. 2005. A problem-based introduction to nuclear sciences. Proceedings of the 2005 ASEE Annual Conference and Exposition, Portland, OR, June 12 - 15. 
[9] Jonassen, D. H. 2000. Toward a design theory of problem solving. Educational Technology: Research and Development, 48(4): 63-85.

[10] Jonassen, D. H. and Rohrer-Murphy, L. 1999. Activity theory as a framework for designing constructivist learning environments. Educational Technology: Research \& Development, 47(1): 61-79.

[11] Blair, J. A. and Johnson, R. H. 1987. Argumentation as dialectical. Argumentation, 1(1): 41-56.

[12] Kuhn, D. 1991. The Skills of Argument. Cambridge University Press: Cambridge.

[13] Kuhn, D. 1992. Thinking as argument. Harvard Educational Review, 62(2): 155-178.

[14] Kuhn, D. 1993. Science as argument: Implications for teaching and learning scientific thinking. Science Education, 77(3): 319-337.

[15] Kahn, H. 1965. On Escalation: Metaphor and Scenarios. Praeger: New York.

[16] Ramirez Apud, T., López-Malo, A., and Palou, E. 2013. Problem-Solving Learning Environments for an Introduction to Food Engineering Course. Proceedings of the 2013 ASEE Annual Conference and Exposition, Atlanta, GA, June 23-26.

[17] Cho, K. L., and Jonassen, D. H. 2003. The effects of argumentation scaffolds on argumentation and problem solving. Educational Technology: Research \& Development, 50(3): 5-22.

[18] Yates, J. F. and Tschirhart, M. D. 2006. Decision-making expertise, in The Cambridge Handbook of Expertise and Expert Performance (K. A. Ericsson, N. Charness, P. F. Feltovich, and R. R. Hoffman, eds.). Cambridge University Press: Cambridge.

[19] Perrenet, J. C., Bouhuijs, P. A. J., and Smits, J. G. M. M. 2000. The suitability of problem-based learning for engineering education: theory and practice. Teaching in Higher Education, 5(3): 345-358.

[20] Duschl, R. A., and Osborne, J. 2002. Supporting and promoting argumentation discourse in science education. Studies in Science Education, 38(1): 39-72.

[21] Nussbaum, E. M. and Sinatra, G. M. 2003. Argument and conceptual engagement. Contemporary Educational Psychology, 28 (3): 384-395. 